\title{
Effect of statins on atrial fibrillation after cardiac surgery: A duration- and dose-response meta-analysis
}

\author{
Wendy T. Chen, PharmD, ${ }^{\text {a,c }}$ Guru M. Krishnan, MD, ${ }^{\mathrm{b}}$ Nitesh Sood, MD, ${ }^{\mathrm{d}}$ Jeffrey Kluger, MD, ${ }^{\mathrm{d}}$ and \\ Craig I. Coleman, PharmD ${ }^{\mathrm{a}, \mathrm{c}}$
}

Objective: This meta-analysis of randomized, controlled trials evaluated effects of statins on postoperative atrial fibrillation risk after cardiac surgery.

\begin{abstract}
Methods: Randomized, controlled trials evaluating statins in cardiac surgery were selected from MEDLINE (1996-August 2009), Cochrane CENTRAL Register, and manual review of references without any language restrictions. End points examined included postoperative atrial fibrillation, intensive care unit stay, and total hospital stay. Meta-regression analyses were conducted to determine whether statins' effects were duration or dose dependent. A random-effects model was used in all instances.
\end{abstract}

Results: Eight trials $(\mathrm{n}=774)$ were identified and subjected to meta-analysis. Statins reduced postoperative atrial fibrillation risk (relative risk $0.57,95 \%$ confidence interval $0.45-0.72, P<.0001$, risk difference $-0.14,95 \%$ confidence interval -0.20 to $-0.08, P<.0001$, number needed to treat 8 ) and total hospital stay (weighted mean difference -0.66 days, $95 \%$ confidence interval -1.01 to -0.30 days, $P=.0004$ ) relative to placebo. Intensive care unit stay was also reduced (weighted mean difference -0.17 days, $95 \%$ confidence interval -0.37 to 0.03 days, $P=.09$ ) but did not meet prespecified criteria for statistical significance. Metaregression analysis revealed association between duration of preoperative statin prophylaxis and postoperative atrial fibrillation risk reduction ( $3 \%$ reduction per day, $P=.008$ ). No association was found between statin dose used and risk reduction $(P=.47)$.

Conclusions: Evidence suggests that statins are associated with reduced risk of postoperative atrial fibrillation and shorter hospital stay after cardiac surgery and that earlier therapy results in more profound benefit. (J Thorac Cardiovasc Surg 2010;140:364-72)

One of the most common complications after cardiac surgery (coronary artery bypass grafting or valve surgery) is the development of postoperative atrial fibrillation (AF). ${ }^{1-3}$ Although typically self-limiting, postoperative AF can increase a patient's risk for hemodynamic instability and stroke. Moreover, it prolongs hospital stay and increases total hospital costs. ${ }^{3,4} \beta$-Blockers and amiodarone are commonly used to prevent postoperative AF; even when these agents are used, however, the development of postoperative $\mathrm{AF}$ is still common. ${ }^{4-6}$

Inflammation may be a causal factor in the development of postoperative AF. ${ }^{1,7-9}$ Because of the ability of hydroxymethylglutaryl coenzyme A reductase inhibitors (statins) to attenuate inflammation, ${ }^{10-11}$ researchers have shown great interest in the relationship between statin use

From the University of Connecticut Schools of Pharmacy ${ }^{\mathrm{a}}$ and Medicine, ${ }^{\mathrm{b}}$ Storrs and Farmington, Conn; and the Departments of Drug Information ${ }^{\mathrm{c}}$ and Cardiology, ${ }^{\mathrm{d}}$ Hartford Hospital, Hartford, Conn.

Disclosures: None.

Received for publication Nov 20, 2009; revisions received Feb 12, 2010; accepted for publication Feb 25, 2010; available ahead of print April 12, 2010.

Address for reprints: Craig I. Coleman, PharmD, Associate Professor of Pharmacy Practice, University of Connecticut School of Pharmacy, 80 Seymour St, Hartford, CT 06102-5037 (E-mail: ccolema@harthosp.org).

$0022-5223 / \$ 36.00$

Copyright (c) 2010 by The American Association for Thoracic Surgery doi:10.1016/j.jtcvs.2010.02.042 before cardiac surgery and the subsequent development of postoperative AF. Previous meta-analyses have evaluated this topic, but their findings were driven by observational studies and consequently subject to bias. ${ }^{12,13}$ More recently, well-designed randomized, controlled trials have appeared in the literature; however, these trials have included relatively small numbers of patients and statin regimens varying in both duration and dosing intensity and therefore have shown mixed results. To understand better the effects of statins on postoperative AF and subsequent hospital stay after cardiac surgery, we performed metaanalysis and duration- and dose-response metaregression analyses of relevant randomized, controlled trials.

\section{MATERIALS AND METHODS}

A protocol was prospectively developed outlining the criteria for trial selection, outcomes of interest, the approach to assessing trial quality, and the statistical methodology. Preparation of this report was in accordance with the Preferred Reporting Items for Systematic Reviews and Meta-Analyses (PRISMA) statement for the reporting of systematic reviews and meta-analyses. $^{14}$

\section{Study Selection}

A systematic literature search of MEDLINE (1996-August 2009) and the Cochrane CENTRAL Register (2009, issue 2) was conducted to identify all relevant trials. The MEDLINE search strategy used in OVID, shown in Appendix 1, used the Cochrane Collaboration's Highly Sensitive Search 


\section{Abbreviations and Acronyms \\ $\mathrm{AF} \quad=$ atrial fibrillation \\ $\mathrm{CI} \quad=$ confidence interval \\ $\mathrm{RR} \quad=$ relative risk \\ ICU = intensive care unit}

Strategy sensitivity-maximizing version. ${ }^{15}$ Results were limited to trials in human subjects. No language restrictions were imposed. A search of Google Scholar and a manual search of references from reports of clinical trials or review articles to identify additional relevant studies were also conducted.

Included trials had (1) to be randomized trials of a statin, (2) to be placebo controlled or open label, and (3) to report data on either the proportion of patients with postoperative AF or total hospital and intensive care unit (ICU) stays. With these prespecified inclusion criteria, 3 investigators (W.T.C., G.M.K., and C.I.C.) reviewed all potentially relevant articles independently, with disagreement among investigators resolved by consensus. When applicable, efforts were made to contact investigators for clarification or additional required data.

\section{Validity Assessment}

The following methodologic features most relevant to the control of bias were assessed: randomization, random allocation concealment, masking of treatment allocation, blinding, and reporting of withdrawals. Jadad scores were calculated to aid in the identification of reports with overall weaker study methodologies. ${ }^{16}$ All studies were reviewed and evaluated by 2 reviewers (W.T.C. and G.M.K.), with disagreement between investigators resolved by consensus.

\section{Data Abstraction}

Two investigators (W.T.C. and G.M.K.) independently abstracted all data with a standardized data-abstraction tool, and disagreements were resolved by a third party (C.I.C.). The following information was sought from each article: author identification, year of publication, study design (method of random allocation, extent of blinding), study population and perioperative characteristics, sample size, duration of patient follow-up, statin regimen used (drug, dose, and duration), type of surgery performed (coronary artery bypass grafting, valve, or combination surgery), use of cardiopulmonary bypass, and definitions of and data for aforementioned study end points. Attempts were made to contact authors of included studies to clarify or collect additional data.

\section{Statistical Analysis}

The incidence of postoperative $\mathrm{AF}$ was treated as a dichotomous variable, and total hospital and ICU stays were treated as continuous variables. Information from individual trials was combined with a DerSimonian and Laird random-effects model. The pooled estimates of effect were reported as either relative risks (RRs) with risk differences (absolute risk reductions) and numbers needed to treat (for postoperative AF) or weighted mean differences (for stay end points) with accompanying $95 \%$ confidence intervals (CIs). Calculations of RRs are problematic for individual studies with an absence of events in the treatment or placebo group. For these studies, a nominal value $(0.5)$ was added in all $2 \times 2$ cells to enable calculation of RRs. ${ }^{15}$

Statistical heterogeneity was addressed with the $\mathrm{I}^{2}$ statistic, which assesses the degree of inconsistency across studies and ranges from $0 \%$ to $100 \%$, with higher percentages representing higher likelihood of heterogeneity. Whereas categorization of values for $\mathrm{I}^{2}$ may not be appropriate in all situations, $\mathrm{I}^{2}$ values of $25 \%, 50 \%$, and $75 \%$ have been regarded as representative of low, medium, and high statistical heterogeneities, respectively. We used visual inspection of funnel plots, Egger's weighted regression statistics, and the trim and fill method to assess for and quantify the effects of publication bias. The trim and fill method uses funnel plot symmetry to estimate the number of "missing" studies and the magnitudes of their effects. It estimates the overall effect size again after imputation of potentially missing studies into the meta-analysis to determine whether the results of the original analysis are replicated. Statistics were performed with StatsDirect statistical software, version 2.7.2 (StatsDirect Ltd, Altrincham, United Kingdom), and MIX statistical software (Bax L, Yu LM, Ikeda N, Tsuruta N, Moons KG. MIX: comprehensive free software for meta-analysis of causal research data-version 1.7. 2008. Available at http://www.mix-formeta-analysis.info).

To establish the effect of heterogeneity between studies on the conclusions of this meta-analysis, subgroup and sensitivity analyses were conducted. The effect of variations in surgery type (involvement of valve surgery), surgical technique (excluding studies with any use of off-pump cardiopulmonary bypass surgery), and methodological quality (excluding studies with Jadad scores $<3$ ) were assessed. In addition, an analysis excluding trials with control rates of postoperative $\mathrm{AF}$ at the extreme ends or outside the norm was conducted. ${ }^{2}$ Finally, the effect of alternatively using a fixed-effect (Mantel-Haenszel) model for pooling data was evaluated.

We further evaluated the effects of preoperative statin duration and dosing intensity (all statin doses converted to atorvastatin equivalents with the following ratios: atorvastatin $10 \mathrm{mg}$ equivalent to simvastatin $5-20 \mathrm{mg}$, pravastatin $10-40 \mathrm{mg}$, or fluvastatin $20-80 \mathrm{mg}$; atorvastatin $20 \mathrm{mg}$ equivalent to simvastatin $40 \mathrm{mg}$, pravastatin $80 \mathrm{mg}$, or rosuvastatin $5 \mathrm{mg}$; atorvastatin $40 \mathrm{mg}$ equivalent to simvastatin $80 \mathrm{mg}$ or rosuvastatin $10 \mathrm{mg}$; and atorvastatin $80 \mathrm{mg}$ equivalent to rosuvastatin $20 \mathrm{mg}$ ) on postoperative $\mathrm{AF}$ risk with random-effects metaregression estimation through iterative maximum likelihood. Metaregression analysis is an indirect way to examine the possibility of effect modification by duration of treatment. The logarithmically transformed RR of postoperative AF was examined. Metaregression analysis was performed with SPSS software, version 17.0 (SPSS Inc, Chicago, Ill).

\section{RESULTS}

The flow of trial inclusion and exclusion is depicted in Figure 1. Ultimately, 8 randomized controlled trials published between 1999 and 2009 from 6 different countries met our eligibility criteria. ${ }^{17-24}$ Key characteristics of included trials can be found in Table 1. Individual trial sizes ranged from 40 to 200 patients, and the total sample size was 774 (389 patients in the statin group and 385 patients in the control group). Specific statins used in trials included the following: atorvastatin (20 and $40 \mathrm{mg})$, fluvastatin $(80 \mathrm{mg})$, pravastatin $(40 \mathrm{mg})$, rosuvastatin $(20 \mathrm{mg})$, and simvastatin (20 $\mathrm{mg}$ ). This corresponds to an atorvastatin dosing equivalent range of 10 to $80 \mathrm{mg}$. Preoperative duration of statin use ranged from as little as 2 days to as long as 4 weeks (2 days -3 weeks for trials reporting the postoperative AF end point). Only 1 trial allowed patients undergoing valve surgery (with or without coronary artery bypass grafting) to be randomly allocated. ${ }^{17}$ Similarly, only 1 trial allowed patients undergoing off-pump surgery to be enrolled. ${ }^{18}$ Data on the routine use of postoperative $\beta$-blockers and amiodarone to prevent postoperative AF were not consistently reported within trials. Six of the 8 included trials evaluated the postoperative $\mathrm{AF}$ end point, ${ }^{17-22}$ whereas 5 and 6 trials evaluated total ICU stay ${ }^{18,21-24}$ and total hospital stay, ${ }^{17-19,22-24}$ respectively. Definitions and duration of monitoring for postoperative $\mathrm{AF}$ were not detailed in 3 trials. $^{20-22}$ Of the 

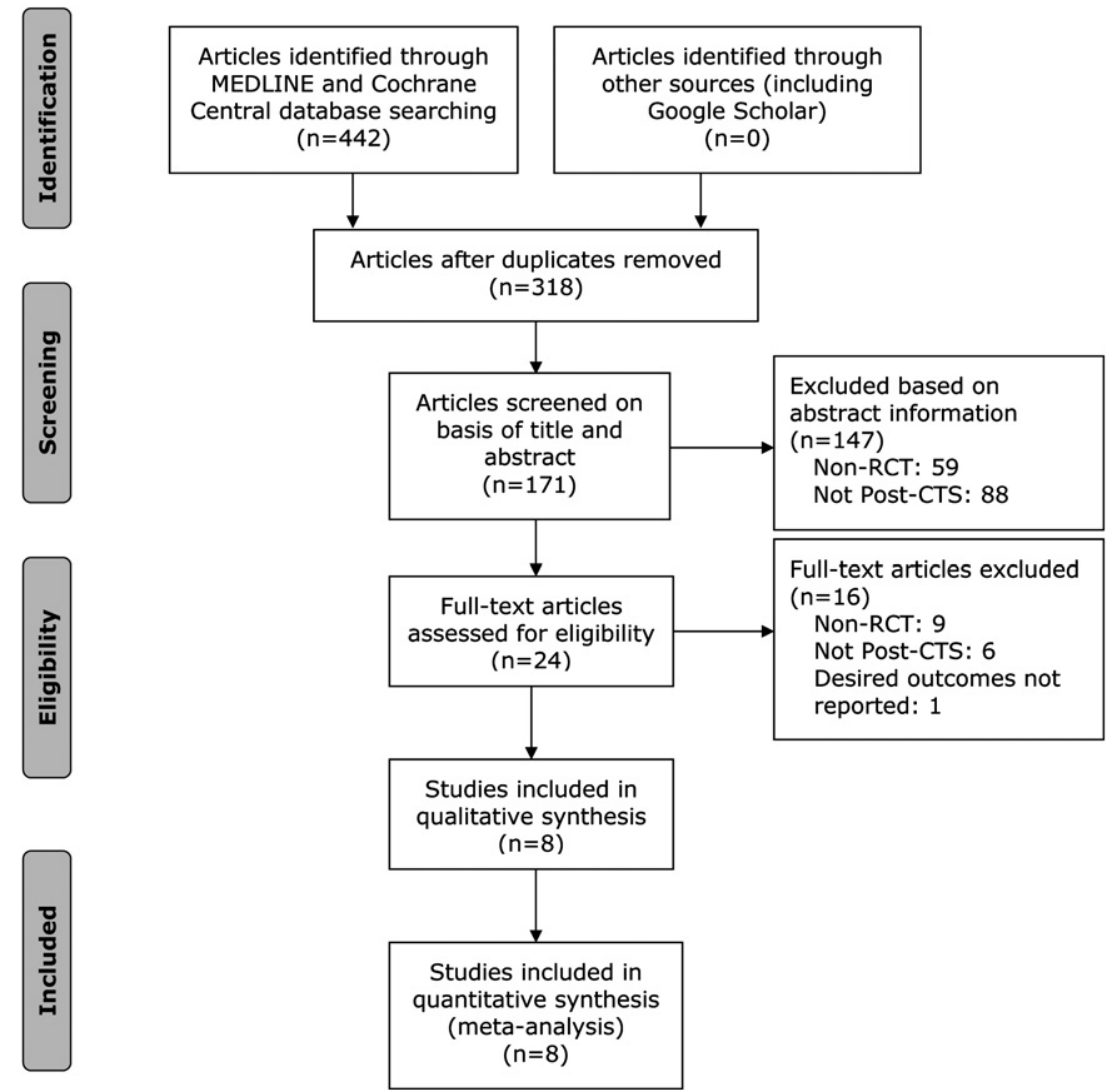

FIGURE 1. Preferred Reporting Items for Systematic Reviews and Meta-Analyses (PRISMA) flow chart. RCT, Randomized, controlled trial; $C T S$, cardiothoracic surgery.

remaining 3 trials, 2 defined postoperative $\mathrm{AF}$ as any documented $\mathrm{AF}$ longer than 5 minutes in duration or $\mathrm{AF}$ episodes requiring intervention for symptoms or hemodynamic compromise and assessed patients with telemetric monitoring for a minimum of 6 postoperative days. ${ }^{17,18}$ The last trial used electrocardiograms taken on admission to the ICU, 12 hours later, and every day thereafter until hospital discharge. ${ }^{19}$

\section{Quantitative Data Synthesis}

Postoperative AF. On meta-analysis of the 6 trials $(n=651)$ evaluating postoperative $\mathrm{AF},{ }^{17-22}$ statin use was found to reduce patients' RR of development of postoperative $\mathrm{AF}$ by $43 \%$ (RR 0.57, 95\% CI 0.45-0.72; Figure 2) and their absolute risk by $14 \%(95 \% \mathrm{CI} 8 \%-20 \%)$. This corresponds to a number needed to treat of $8(95 \%$ CI 5-13). No statistical heterogeneity was observed for these analyses $\left(\mathrm{I}^{2}=0\right.$ for both). The Egger's statistic $P$ value suggested a low likelihood of publication bias $(P>.17$ for both). Trim and fill analysis suggests that any publication bias that might exist was not likely to effect our meta-analyses' overall conclusions regarding postoperative $\mathrm{AF}$ (Table 2).

Metaregression analysis suggested a statistically significant correlation $(\operatorname{Ln} \mathrm{RR}=[-0.0283 \times$ Duration $]-0.4781$,
$P=.008)$ between preoperative duration of statin use and a patient's RR reduction of postoperative AF (Figure 3 and Table 3). No statistically significant correlation was seen when evaluating statin dose $(P=.47)$. The meta-analyses' conclusions regarding postoperative AF were not altered by conduction of various sensitivity analyses.

Length of stay. Pooled analysis of 5 trials ${ }^{18,21-24}(\mathrm{n}=331)$ suggested a 0.17 day decrease in ICU stay with preoperative statin use; however, this end point failed to reach statistical significance $(P=.10)$. On meta-analysis of 6 trials $(\mathrm{n}=687)$ evaluating total hospital stay, ${ }^{17-19,22-24}$ statin use was found to reduce patients' stay statistically significantly by twothirds of a day. Small to moderate degrees of statistical heterogeneity were observed in both these analyses $\left(\mathrm{I}^{2}=24 \%\right.$ and $47 \%$, respectively). As with the postoperative AF end point, publication bias was deemed to be unlikely (Egger's $P$ value $>0.19$ for both) or alter our meta-analyses' overall conclusions for these end points. The meta-analytic conclusions regarding ICU and total stays were not altered by conduction of various sensitivity analyses.

\section{DISCUSSION}

In this meta-analysis of 8 randomized, controlled trials, patients receiving statins had a lower risk of development 
TABLE 1. Characteristics of included randomized controlled trials of statins in cardiac surgery

\begin{tabular}{|c|c|c|c|c|c|c|c|c|}
\hline & $\begin{array}{c}\text { Berkan, } \\
2009^{23}\end{array}$ & $\begin{array}{l}\text { Caorsi, } \\
2008^{20}\end{array}$ & $\begin{array}{c}\text { Mannacio, } \\
2008^{19}\end{array}$ & $\begin{array}{l}\text { Song, } \\
2008^{18}\end{array}$ & $\begin{array}{c}\text { Tamayo, } \\
2008^{21}\end{array}$ & $\begin{array}{l}\text { Chello, } \\
2006^{22}\end{array}$ & $\begin{array}{l}\text { Patti, } \\
2006^{17}\end{array}$ & $\begin{array}{c}\text { Christenson, } \\
1999^{24} \\
\end{array}$ \\
\hline \multicolumn{9}{|c|}{ Demographic data } \\
\hline \multicolumn{9}{|c|}{ No. of patients } \\
\hline Statin & 23 & 21 & 100 & 62 & 22 & 20 & 101 & 40 \\
\hline Control & 23 & 22 & 100 & 62 & 22 & 20 & 99 & 37 \\
\hline \multicolumn{9}{|c|}{ Age (y, mean) } \\
\hline Statin & 65 & 68 & 61 & 62 & 68 & 66 & 66 & 63 \\
\hline Control & 68 & 68 & 59 & 64 & 68 & 64 & 67 & 64 \\
\hline \multicolumn{9}{|c|}{ Sex $(\%$ male $)$} \\
\hline Statin & 61 & 81 & 75 & 63 & 77 & 80 & 79 & 78 \\
\hline Control & 65 & 86 & 70 & 68 & 82 & 75 & 68 & 84 \\
\hline \multicolumn{9}{|c|}{ Medical history } \\
\hline \multicolumn{9}{|c|}{ Diabetes mellitus (\%) } \\
\hline Statin & 35 & 38 & 0 & 47 & 27 & 0 & 32 & 23 \\
\hline Control & 39 & 41 & 0 & 52 & 41 & 0 & 42 & 24 \\
\hline \multicolumn{9}{|c|}{ Previous myocardial infarction $(\%)$} \\
\hline Statin & NR & 0 & 21 & 13 & 0 & 0 & 47 & 55 \\
\hline Control & NR & 0 & 25 & 8 & 0 & 0 & 38 & 59 \\
\hline \multicolumn{9}{|c|}{ Previous atrial fibrillation (\%) } \\
\hline Statin & NR & NR & NR & 0 & NR & NR & 0 & NR \\
\hline Control & NR & NR & NR & 0 & NR & NR & 0 & NR \\
\hline \multicolumn{9}{|c|}{ Previous medications } \\
\hline \multicolumn{9}{|c|}{ Angiotensin-converting enzyme inhibitors (\%) } \\
\hline Statin & NR & 0 & 22 & 57 & $32 *$ & NR & 47 & NR \\
\hline Control & NR & 0 & 28 & 50 & $55^{*}$ & NR & 52 & NR \\
\hline \multicolumn{9}{|c|}{ Amiodarone $(\%)$} \\
\hline Statin & NR & NR & 10 & NR & NR & NR & 1 & NR \\
\hline Control & NR & NR & 12 & NR & NR & NR & 1 & NR \\
\hline \multicolumn{9}{|c|}{$\beta$-Blockers $(\%)$} \\
\hline Statin & NR & NR & 73 & 73 & 27 & 30 & 72 & NR \\
\hline Control & NR & NR & 68 & 69 & 46 & 35 & 60 & NR \\
\hline \multicolumn{9}{|l|}{ Surgery type } \\
\hline \multicolumn{9}{|c|}{ On pump (\%) } \\
\hline Statin & 100 & 100 & 100 & 0 & 100 & 100 & 100 & 100 \\
\hline Control & 100 & 100 & 100 & 0 & 100 & 100 & 100 & 100 \\
\hline \multicolumn{9}{|c|}{ Coronary artery bypass grafting $(\%)$} \\
\hline Statin & 100 & 100 & 100 & 100 & 100 & 100 & 83 & 100 \\
\hline Control & 100 & 100 & 100 & 100 & 100 & 100 & 75 & 100 \\
\hline \multicolumn{9}{|c|}{ Valve surgery $(\%)$} \\
\hline Statin & 0 & 0 & 0 & 0 & 0 & 0 & $16 \dagger$ & 0 \\
\hline Control & 0 & 0 & 0 & 0 & 0 & 0 & $25 \dagger$ & 0 \\
\hline \multicolumn{9}{|c|}{ Perioperative data } \\
\hline \multicolumn{9}{|c|}{ CPB time (min) } \\
\hline Statin & 122 & 94 & 81 & NA & 107 & 97 & 113 & 78 \\
\hline Control & 113 & 94 & 84 & NA & 96 & 94 & 105 & 82 \\
\hline Crossclamp & ne $(\min )$ & & & & & & & \\
\hline Statin & 73 & 63 & 42 & NA & 70 & 49 & 76 & 64 \\
\hline Control & 71 & 63 & 40 & NA & 63 & 52 & 73 & 61 \\
\hline Inotrope us & & & & & & & & \\
\hline Statin & 9 & NR & 11 & 63 & 60 & 25 & 30 & NR \\
\hline Control & 30 & NR & 25 & 68 & 41 & 30 & 25 & NR \\
\hline Intra-aortic & lloon pump & rt (\%) & & & & & & \\
\hline Statin & 4 & NR & 0 & 5 & NR & NR & NR & NR \\
\hline Control & 13 & NR & 1 & 3 & NR & NR & NR & NR \\
\hline
\end{tabular}


TABLE 1. Continued

\begin{tabular}{|c|c|c|c|c|c|c|c|c|}
\hline & $\begin{array}{c}\text { Berkan, } \\
2009^{23}\end{array}$ & $\begin{array}{l}\text { Caorsi, } \\
2008^{20}\end{array}$ & $\begin{array}{c}\text { Mannacio, } \\
2008^{19}\end{array}$ & $\begin{array}{l}\text { Song, } \\
2008^{18}\end{array}$ & $\begin{array}{c}\text { Tamayo, } \\
2008^{21}\end{array}$ & $\begin{array}{l}\text { Chello, } \\
2006^{22}\end{array}$ & $\begin{array}{l}\text { Patti, } \\
\text { 2006 }^{17}\end{array}$ & $\begin{array}{c}\text { Christenson, } \\
1^{1999^{24}}\end{array}$ \\
\hline Intervention & $\begin{array}{l}\text { Fluvastatin } \\
80 \mathrm{mg} / \mathrm{d} \text { vs } \\
\text { placebo for } \\
21 \mathrm{~d} \text { preop }\end{array}$ & $\begin{array}{l}\text { Pravastatin } \\
40 \mathrm{mg} / \mathrm{d} \text { for } \\
48 \mathrm{~h} \text { preop, } \\
\text { extra } 40 \mathrm{mg} \\
\text { dose } 1 \mathrm{~h} \text { post } \\
\mathrm{CPB} \text {, contd }\end{array}$ & $\begin{array}{l}\text { Rosuvastatin } \\
20 \mathrm{mg} / \mathrm{d} \text { vs } \\
\text { placebo for } \\
7 \mathrm{~d} \text { preop }\end{array}$ & $\begin{array}{l}\text { Atorvastatin } \\
\qquad \begin{array}{l}20 \mathrm{mg} / \mathrm{d} \text { for } \\
3 \mathrm{~d} \text { preop, } \\
\text { contd for } 30 \\
\mathrm{~d} \text { postop vs } \\
\text { no treatment }\end{array}\end{array}$ & $\begin{array}{l}\text { Simvastatin } \\
20 \mathrm{mg} / \mathrm{d} \text { for } \\
21 \mathrm{wk} \text { preop } \\
\text { vs no } \\
\text { treatment }\end{array}$ & $\begin{array}{l}\text { Atorvastatin } \\
20 \mathrm{mg} / \mathrm{d} \mathrm{vs} \\
\text { placebo for } \\
21 \mathrm{~d} \text { preop }\end{array}$ & $\begin{array}{l}\text { Atorvastatin } 40 \\
\mathrm{mg} / \mathrm{d} \text { vs } \\
\text { placebo for } \\
7 \mathrm{~d} \text { preop, } \\
\text { contd to } \\
\text { discharge }\end{array}$ & $\begin{array}{l}\text { Simvastatin } \\
20 \mathrm{mg} / \mathrm{d} \text { for } \\
28 \mathrm{~d} \text { preop } \\
\text { vs no } \\
\text { treatment }\end{array}$ \\
\hline
\end{tabular}

no treatment

Jadad scoret $\quad 3(1,2,1) \quad 1(1,0,0)$

$3(1,2,0) \quad 3(2,0,1)$

$2(1,1,0)$

$3(1,2,0)$

$4(2,2,0)$

$1(1,0,0)$

$N R$, Not reported; $C P B$, cardiopulmonary bypass; $N A$, not applicable; preop, preoperatively; contd, continued; postop, postoperatively. * Or angiotensin II receptor blockers. $\dagger$ Valve surgery with or without coronary artery bypass grafting. 抽ad score presented as overall score with subscores for randomization (up to 2 points), double-blinding (up to 2 points), description of withdrawals (up to 1 point), and (overall score).

of postoperative AF (RR 0.57; number needed to treat 8 ) and shorter hospital stay ( -0.66 days) after cardiac surgery. Statistically nonsignificant reductions in ICU stay were also observed. Because of the small number of studies and patients included in this later mentioned analysis, however, it may be premature to conclude that statins do not reduce ICU stay as well.

Inflammation has been postulated as among the mechanisms underlying the development of postoperative AF in patients undergoing cardiac surgery.,7-9 Because current evidence suggests that statins have potent antiinflammatory effects in cardiac surgical patients, ${ }^{25-27}$ the significant $43 \% \mathrm{RR}$ reduction in postoperative AF seen in this current meta-analysis provides further evidence supporting the therapeutic benefits derived from using agents that attenuate the inflammatory response. In particular, corticosteroids, $^{28-30}$ polyunsaturated $n-3$ fatty acids, ${ }^{31,32}$ nonsteroidal anti-inflammatory drugs, ${ }^{33}$ and $N$-acetylcysteine $^{34}$ are all anti-inflammatory agents previously shown to be efficacious in reducing postoperative AF, with RR reductions ranging from $20 \%{ }^{34}$ to $66 \%{ }^{33}$

A study by Plenge and colleagues ${ }^{35}$ evaluating the time to onset of statins' anti-inflammatory effects suggests that their effects are not of acute onset but rather occur with time. In this study, a profound anti-inflammatory effect with simvastatin $40 \mathrm{mg}$ (measured by high-sensitivity $\mathrm{C}$-reactive protein lowering) was not apparent until around day 7 and did not reach statistical significance until day 14 . Thus this trial suggests that the earlier a statin can be initiated before surgery, the more profound will be the antifibrillatory benefit achieved by patients. To the best of our knowledge, ours is the first analysis of any kind to assess whether a relationship in fact exists between preoperative duration of statin use and effect on postoperative AF. Of note, we demonstrated a both statistically and clinically significant duration-effect interaction, equating to approximately a $3 \%$ risk reduction in postoperative AF per preoperative day of statin use $(P=.008)$. Although this finding is provocative, it needs to be confirmed in a randomized trial.
Previous research has suggested that a dose-response relationship with statins and postoperative AF may also exist. $^{36-38}$ Lertsburapa and colleagues ${ }^{36}$ conducted a nested case-control study with data from the randomized, controlled Atrial Fibrillation Suppression Trials I, II, and III and found that higher statin doses (atorvastatin equivalent dose $\geq 40 \mathrm{mg} / \mathrm{d}$ ) were associated with greater reduction in postoperative AF than were lower doses. This finding was later corroborated by observational studies conducted by Kourliouros and associates ${ }^{37}$ and Mathani and coworkers. ${ }^{38}$ Our metaregression analysis failed to confirm the findings of these 3 studies $(P=.47)$. Despite this failure, however, we cannot rule out the possibility that such a relationship does in fact exist, because our analysis contained only a few studies and may have been underpowered to detect it.

Some limitations to this meta-analysis should be noted. First, it is possible that preoperative statin use in included trials is serving as a surrogate for higher socioeconomic status. Because better socioeconomic status has been found to be associated with decreased postoperative complications in patients undergoing cardiac surgery, it is possible that our findings do not represent a innate benefit of statins. ${ }^{39,40}$ Second, publication bias is always a concern when conducting a meta-analysis. ${ }^{15}$ Because of the small number of trials included in our meta-analysis, it was difficult to rule out the presence of publication bias solely by visual inspection of funnel plots. That being said, Egger's regression statistic $P$ values did suggest that publication bias was less likely, and trim and fill analyses suggested that any publication bias present was not likely to affect overall study conclusions. Next, because of sparse and inconsistent reporting across trials, we were unable to assess the impact of heterogeneous definitions of postoperative AF or variations in the use of routine prophylactic therapies (eg, $\beta$ blockers, amiodarone) on our meta-analytic conclusions. With respect to the latter of these limitations, because $\beta$ blockers and amiodarone do not reduce postoperative AF through anti-inflammatory mechanisms, we would expect any interaction with statins to be minimal. Finally, we 


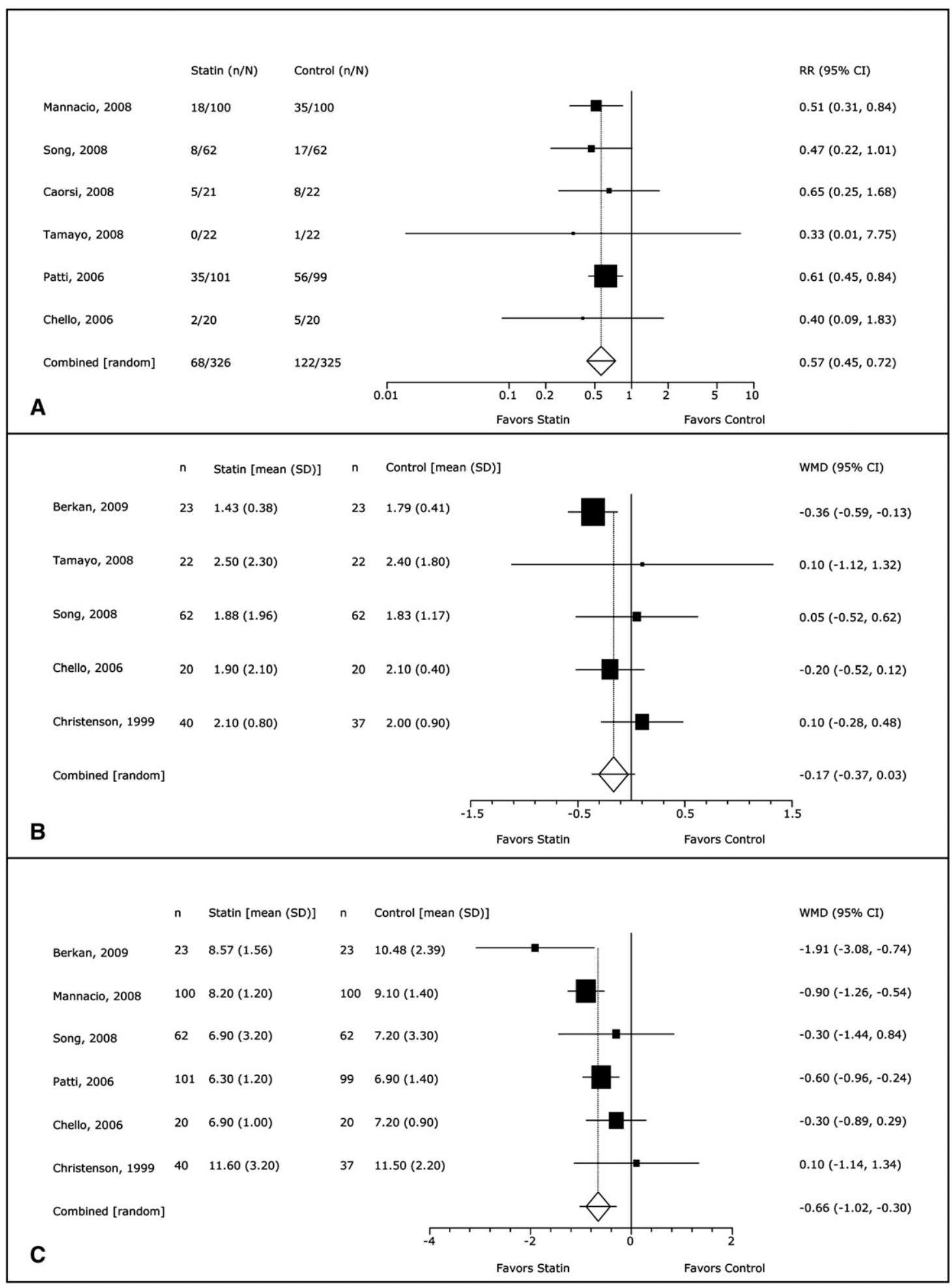

FIGURE 2. Statins' effects on postoperative atrial fibrillation (A), intensive care unit stay (B), and total hospital stay (C). All pooled results were calculated with DerSimonian and Laird random-effects model. $R R$, Relative risk; $C I$, confidence interval; $W M D$, weighted mean difference. 
TABLE 2. Results of sensitivity analyses

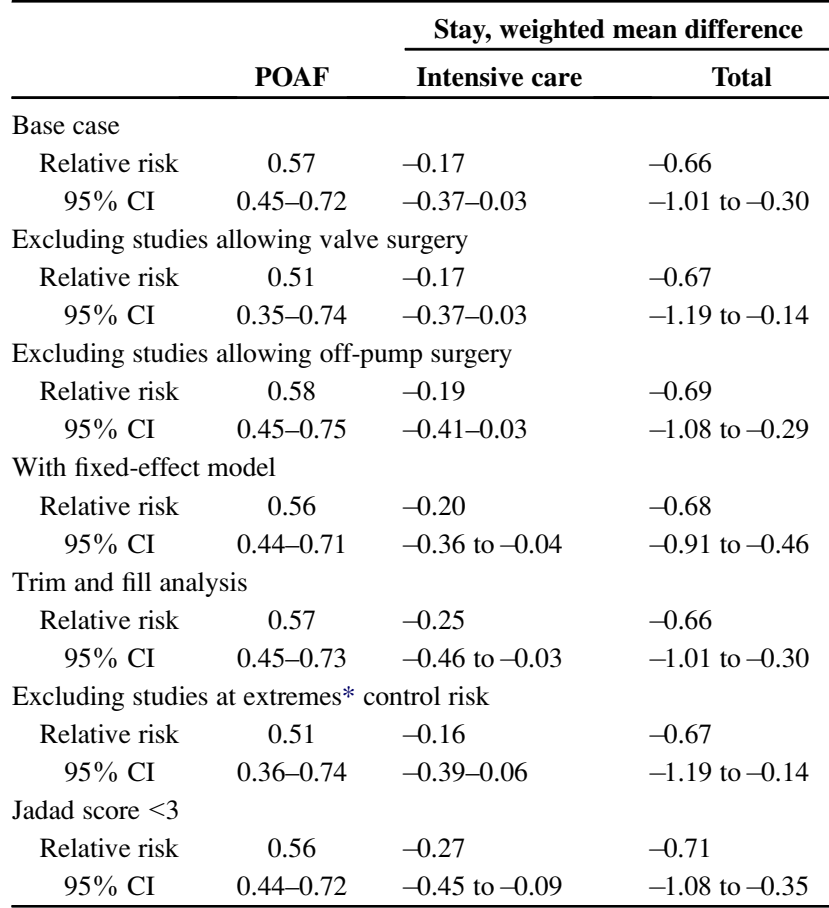

$P O A F$, Postoperative atrial fibrillation; $C I$, confidence interval. *Control risks $5 \%$ for Tamayo, $57 \%$ for Patti (mean control risk $31 \%$ ).

were not able to assess additional clinical end points, including stroke, myocardial infarction, and death, because of sporadic reporting and low event rates. Larger clinical trials will be required to evaluate these end points in the future.

\section{CONCLUSIONS}

Evidence suggests that statins are associated with a reduced risk of postoperative AF and a shorter hospital stay af-

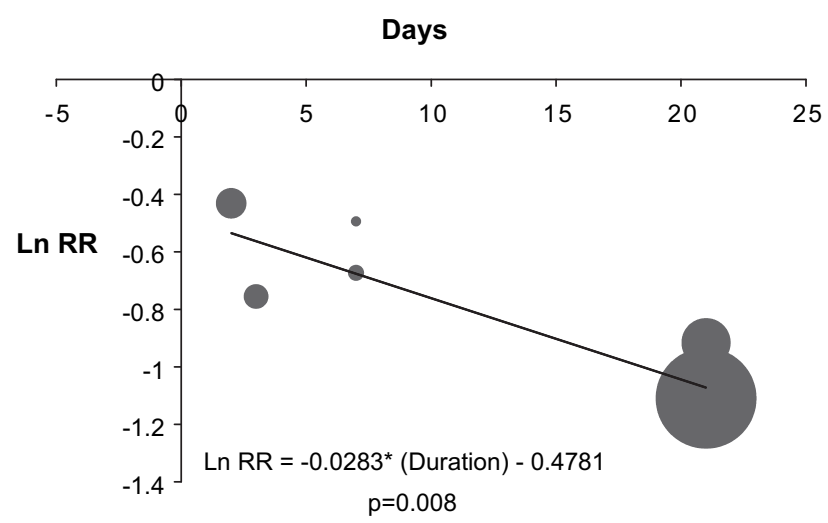

FIGURE 3. Risk ratio $(R R)$ of postoperative atrial fibrillation associated with duration of preoperative statin use. Greater weight of study corresponds to larger area of circle and to greater contribution of study to overall pooled effect. Superimposed line was obtained by conducting randomeffects metaregression analysis with restricted maximum likelihood method to estimate residual variance resulting from heterogeneity.
TABLE 3. Risk ratio of postoperative atrial fibrillation associated with statin use by increasing increments in preoperative statin duration

\begin{tabular}{cc}
\hline Duration (d) & Risk ratio* \\
\hline 2 & 0.59 \\
3 & 0.57 \\
7 & 0.51 \\
14 & 0.42 \\
21 & 0.34 \\
\hline
\end{tabular}

*Derived from the following equation: $\operatorname{Ln}(\mathrm{RR})=-0.0283 \times \mathrm{D}-0.4781$, where $\mathrm{RR}$ represents risk ratio and $\mathrm{D}$ represents duration in days $(P=.008)$.

ter cardiac surgery. Data also suggest that earlier therapy results in more profound benefit. Unfortunately, this metaanalysis of relatively small trials does not provide definitive proof of any statin's antifibrillatory benefit. Moreover, the optimal duration and dose of perioperative statins are still a matter of debate. Larger randomized, controlled trials designed to compare different dosing intensities and lengths of statin therapy should therefore be conducted in the future.

We thank Dr Caorsi and colleagues for providing additional data pertaining to their trial.

\section{References}

1. Ramlawi R, Otu H, Mieno S, Boodhwani M, Sodha NR, Clements RT, et al. Oxidative stress and atrial fibrillation after cardiac surgery: a case-control study. Ann Thorac Surg. 2007;84:1166-73.

2. Fuster V, Rydén LE, Cannom DS, Crijns HJ, Curtis AB, Ellenbogen KA, et al. ACC/AHA/ESC 2006 guidelines for the management of patients with atrial fibrillation: a report of the American College of Cardiology/American Heart Association Task Force on Practice Guidelines and the European Society of Cardiology Committee for Practice Guidelines (Writing Committee to Revise the 2001 Guidelines for the Management of Patients with Atrial Fibrillation) developed in collaboration with the European Heart Rhythm Association and the Heart Rhythm Society. J Am Coll Cardiol. 2006;48:e149-246. Erratum in: J Am Coll Cardiol. 2007;50:562.

3. Almassi GH, Schowalter T, Nicolosi AC, Aggarwal A, Moritz TE, Henderson WG, et al. Atrial fibrillation after cardiac surgery: a major morbid event? Ann Surg. 1997;226:501-11.

4. Mathew JP, Fontes ML, Tudor IC, Ramsay J, Duke P, Mazer CD, et al. A multicenter risk index for atrial fibrillation after cardiac surgery. JAMA. 2004;291: 1720-9.

5. Giri S, White CM, Dunn A, Felton K, Freeman-Bosco L, Reddy P, et al. Oral amiodarone for prevention of atrial fibrillation after open heart surgery, the Atrial Fibrillation Suppression Trial (AFIST): a randomised placebo-controlled trial. Lancet. 2001;357:830-6.

6. White CM, Caron MF, Kalus JS, Rose H, Song J, Reddy P, et al. Intravenous plus oral amiodarone, atrial septal pacing, or both strategies to prevent post-cardiothoracic surgery atrial fibrillation: the Atrial Fibrillation Suppression Trial II (AFIST II). Circulation. 2003;108(Suppl. 1):II200-6.

7. Bruins P, te Velthuis H, Yazdanbakhsh AP, Jansen PG, van Hardevelt FW, de Beaumont EM, et al. Activation of the complement system during and after cardiopulmonary bypass surgery: postsurgery activation involves C-reactive protein and is associated with postoperative arrhythmia. Circulation. 1997;96:3542-8.

8. Gaudino M, Andreotti F, Zamparelli R, Di Castelnuovo A, Nasso G, Burzotta F, et al. The $174 \mathrm{G} / \mathrm{C}$ interleukin-6 polymorphism influences postoperative interleukin-6 levels and postoperative atrial fibrillation. Is atrial fibrillation an inflammatory complication? Circulation. 2003;108:195-9.

9. Chung MK, Martin DO, Sprecher D, Wazni O, Kanderian A, Carnes CA, et al. C-reactive protein elevation in patients with atrial fibrillation. Circulation. 2001;104:2886-91.

10. Jialal I, Stein D, Balis D, Grundy SM, Adams-Huet B, Devaraj S. Effect of hydroxymethyl glutaryl coenzyme a reductase inhibitor therapy on high sensitive C-reactive protein levels. Circulation. 2001;103:1933-5. 
11. Kumagai K, Nakashima H, Saku K. The HMG-CoA reductase inhibitor atorvastatin prevents atrial fibrillation by inhibiting inflammation in a canine sterile pericarditis model. Cardiovasc Res. 2004;62:105-11.

12. Liakopoulos OJ, Choi YH, Haldenwang PL, Strauch J, Wittwer T, Dörge H, et al. Impact of preoperative statin therapy on adverse postoperative outcomes in patients undergoing cardiac surgery: a meta-analysis of over 30,000 patients. Eur Heart J. 2008;29:1548-59.

13. Liakopoulos OJ, Choi YH, Kuhn EW, Wittwer T, Borys M, Madershahian N, et al. Statins for prevention of atrial fibrillation after cardiac surgery: a systematic literature review. J Thorac Cardiovasc Surg. 2009;138:678-86. e1.

14. Moher D, Liberati A, Tetzlaff J, Altman D. PRISMA Group. Preferred reporting items for systematic reviews and meta-analyses: the PRISMA statement. Ann Intern Med. 2009;151:264-9. W64.

15. Higgins JP, Green S, editors. Cochrane handbook for systematic reviews of interventions version 5.0.2 [Internet]. London: The Cochrane Collaboration; 2009 [updated September 2009; cited March 17, 2010]. Available from: http://www. cochrane-handbook.org/.

16. Jadad A, Moore RA, Carroll D, Jenkinson C, Reynolds DJ, Gavaghan DJ, et al. Assessing the quality of reports of randomized clinical trials: is blinding necessary? Control Clin Trials. 1996;17:1-12.

17. Patti G, Chello M, Candura D, Pasceri V, D'Ambrosio A, Covino E, et al. Randomized trial of atorvastatin for reduction of postoperative atrial fibrillation in patients undergoing cardiac surgery: results of the ARMYDA-3 (Atorvastatin for Reduction of MYocardial Dysrhythmia After cardiac surgery) study. Circulation. 2006; 114:1455-61.

18. Song YB, On YK, Kim JH, Shin DH, Kim JS, Sung J, et al. The effects of atorvastatin on the occurrence of postoperative atrial fibrillation after off-pump coronary artery bypass grafting surgery. Am Heart J. 2008;156:e9-16.

19. Mannacio VA, Iorio D, De Amicis V, Di Lello F, Musumeci F. Effect of rosuvastatin pretreatment on myocardial damage after coronary surgery: A randomized trial. J Thorac Cardiovasc Surg. 2008;136:1541-8.

20. Carosi C, Pineda F, Munoz C. Pravastatin immunomodulates IL-6 and C-reactive protein, but not IL-1 and TNF- $\alpha$, in cardio-pulmonary bypass. Eur Cytokine Netw. 2008;19:99-103.

21. Tamayo E, Alonso O, Alvarez FJ, Castrodeza J, Flórez S, di Stefano S. [Effects of simvastatin on acute-phase protein levels after cardiac surgery]. Med Clin (Barc). 2008;130:773-5.

22. Chello M, Patti G, Candura D, Mastrobuoni S, Di Sciascio G, Agrò F, et al. Effects of atorvastatin on systemic inflammatory response after coronary bypass surgery. Crit Care Med. 2006;34:660-7.

23. Berkan O, Katrancioglu N, Ozker E, Ozerdem G, Bakici Z, Yilmaz MB. Reduced P-selectin in hearts pretreated with fluvastatin: a novel benefit for patients undergoing open heart surgery. Thorac Cardiovasc Surg. 2009;57:91-5.

24. Christenson JT. Preoperative lipid-control with simvastatin reduces the risk of postoperative thrombocytosis and thrombotic complications following CABG. Eur J Cardiothorac Surg. 1999; 15:394-9.

25. Chello M, Anselmi A, Spadaccio C, Patti G, Goffredo C, Di Sciascio G, et al. Simvastatin increases neutrophil apoptosis and reduces inflammatory reaction after coronary surgery. Ann Thorac Surg. 2007;83:1374-80.
26. Dereli Y, Ege E, Kurban S, Narin C, Sarigül A, Yeniterzi M. Pre-operative atorvastatin therapy to decrease the systemic inflammatory response after coronary artery bypass grafting. J Int Med Res. 2008;36:1248-54

27. Brull DJ, Sanders J, Rumley A, Lowe GD, Humphries SE, Montgomery HE. Statin therapy and the acute inflammatory response after coronary artery bypass grafting. Am J Cardiol. 2001;88:431-3.

28. Baker WL, White CM, Kluger J, Denowitz A, Konecny CP, Coleman CI. Effect of perioperative corticosteroid use on the incidence of postcardiothoracic surgery atrial fibrillation and length of stay. Heart Rhythm. 2007;4:461-8.

29. Whitlock RP, Chan S, Devereaux PJ, Sun J, Rubens FD, Thorlund K, et al. Clinical benefit of steroid use in patients undergoing cardiopulmonary bypass: a metaanalysis of randomized trials. Eur Heart J. 2008;29:2592-600.

30. Ho KM, Tan JA. Benefits and risks of corticosteroid prophylaxis in adult cardiac surgery: a dose-response meta-analysis. Circulation. 2009;119:1853-66.

31. Calò L, Bianconi L, Colivicchi F, Lamberti F, Loricchio ML, de Ruvo E, et al N-3 Fatty acids for the prevention of atrial fibrillation after coronary artery bypass surgery: a randomized, controlled trial. J Am Coll Cardiol. 2005;45: 1723-8.

32. Heidt MC, Vician M, Stracke SK, Stadlbauer T, Grebe MT, Boening A, et al. Beneficial effects of intravenously administered N-3 fatty acids for the prevention of atrial fibrillation after coronary artery bypass surgery: a prospective randomized study. Thorac Cardiovasc Surg. 2009;57:276-80.

33. Cherku KK, Ghani A, Ahmad F, Pappas P, Silverman PR, Zelinger A, et al. Efficacy of nonsteroidal anti-inflammatory medications for prevention of atrial fibrillation following coronary artery bypass graft surgery. Prev Cardiol. 2004;7 13-8.

34. Baker WL, Anglade MW, Baker EL, White CM, Kluger J, Coleman CI. Use of Nacetylcysteine to reduce post-cardiothoracic surgery complications: a meta-analysis. Eur J Cardiothorac Surg. 2009;35:521-7.

35. Plenge JK, Hernandez TL, Weil KM, Poirier P, Grunwald GK, Marcovina SM, et al. Simvastatin lowers C-reactive protein within 14 days: an effect independent of low-density lipoprotein cholesterol reduction. Circulation. 2002;106:1447-52.

36. Lertsburapa K, White CM, Kluger J, Faheem O, Hammond J, Coleman CI. Preoperative statins for the prevention of atrial fibrillation after cardiothoracic surgery. J Thorac Cardiovasc Surg. 2008;135:405-11.

37. Kourliouros A, De Souza A, Roberts N, Marciniak A, Tsiouris A, Valencia O, et al. Dose-related effect of statins on atrial fibrillation after cardiac surgery. Ann Thorac Surg. 2008;85:1515-20.

38. Mithani S, Akbar MS, Johnson DJ, Kuskowski M, Apple KK, Bonawitz-Conlin J, et al. Dose dependent effect of statins on postoperative atrial fibrillation after cardiac surgery among patients treated with beta blockers. J Cardiothorac Surg. 2009;4:61.

39. Agabiti N, Cesaroni G, Picciotto S, Bisanti L, Caranci N, Costa G, et al. The association of socioeconomic disadvantage with postoperative complications after major elective cardiovascular surgery. J Epidemiol Community Health. 2008; 62:882-9.

40. Gibson PH, Croal BL, Cuthbertson BH, Gibson G, Jeffrey RR, Buchan KG, et al Socio-economic status and early outcome from coronary artery bypass grafting. Heart. 2009;95:793-8. 


\section{Appendix 1. MEDLINE in OVID Search Strategy}

1. Hydroxymethylglutaryl-CoA Reductase Inhibitors/ or hydroxymenthylglutaryl-CoA Reductase inhibitor.mp. or hydroxymethylglutaryl-CoA Reductase inhibitors.mp. or HMG CoA reductase inhibitors.mp. or HMG CoA reductase inhibitor.mp.

2. (statins or statin).mp.

3. (atorvastatin or fluvastatin or lovastatin or pravastatin or rosuvastatin or simvastatin or pitavastatin).mp. [mp=ti, $\mathrm{ab}, \mathrm{tx}, \mathrm{kw}, \mathrm{ct}, \mathrm{ot}, \mathrm{sh}, \mathrm{hw}, \mathrm{nm}]$

4. 1 or 2 or 3

5. thoracic surgery.mp. or Thoracic Surgery/

6. (cardiac surgery or heart surgery or cardiac thoracic surgery or open heart surgery).mp. [mp=ti, ab, tx, kw, ct, ot, sh, hw, nm]

7. cardiopulmonary bypass.mp. or Cardiopulmonary Bypass/
8. (cardiopulmonary bypasses or heart-lung bypass or heart-lung bypasses).mp.

9. coronary artery bypass.mp. or Coronary Artery Bypass/

10. (coronary artery bypasses or coronary artery bypass grafting or CABG or aortocoronary bypass or aortocoronary bypasses or coronary artery bypass surgery).mp.

11. (valve replacement or valve surgery or valvular surgery).mp.

12. 5 or 6 or 7 or 8 or 9 or 10 or 11

13. 4 and 12

14. (randomized controlled trial or controlled clinical trial).pt. or randomized.ab. or placebo.ab. or drug therapy.fs. or randomly.ab. or trial.ab. or group.ab.

15. (animals not (humans and animals)).sh.

16. 14 not 15

17. 16 and 13 